\title{
A discrete choice experiment on preferences of patients with rheumatoid arthritis regarding disease-modifying antirheumatic drugs: the identification, refinement, and selection of attributes and levels
}

This article was published in the following Dove Press journal:

Patient Preference and Adherence

\author{
Elke GE Mathijssen' \\ Milou van Heuckelum² \\ Liset van Dijk ${ }^{3}$ \\ Marcia Vervloet ${ }^{3}$ \\ Simone MT Zonnenberg' \\ Johanna E Vriezekolk' \\ Bart JF van den Bemt ${ }^{2}$ \\ 'Department of Rheumatology, \\ Sint Maartenskliniek, Nijmegen, \\ the Netherlands; ${ }^{2}$ Department of \\ Rheumatology and Pharmacy, Sint \\ Maartenskliniek, Nijmegen, the \\ Netherlands; ${ }^{3}$ Netherlands Institute \\ for Health Services Research (NIVEL), \\ Utrecht, the Netherlands
}

Objective: To comprehensively describe the identification, refinement, and selection of attributes and levels for a discrete choice experiment (DCE) on preferences of patients with rheumatoid arthritis (RA) regarding disease-modifying antirheumatic drugs (DMARDs).

Methods: A mixed-methods approach, consisting of three consecutive steps: a literature review, expert recommendations, and focus groups. Attributes and levels were identified by a scoping review and compiled into a list that was evaluated on its relevance by an expert panel. The list that resulted thereafter was used to inform three focus groups, including 23 patients with RA. New attributes and levels could be identified during the focus groups. Also, a ranking exercise was performed. The patients individually ranked the attributes (ie, the ones on the list and newly identified attributes) by relevance. The patients' individual rankings were summed to derive a ranking at group level and make an a priori selection of the most relevant attributes. The group discussions were transcribed for qualitative analysis.

Results: Nineteen attributes, each specified by two to seven levels, were identified by the scoping review. The expert recommendations resulted in the removal of one attribute. Furthermore, two new attributes and levels were identified and two attributes were split into two. One new attribute was identified during the focus groups. The results of the ranking exercise and qualitative analysis led to the refinement and selection of the following attributes: route of administration, frequency of administration, chance of efficacy, onset of action, risk of serious infections, risk of liver injury, and risk of cancer. Each attribute was specified by three levels.

Conclusion: This study contributes to the limited literature on the development of attributes and levels. Future research should pay more attention to a comprehensive description of this process. It ensures transparency and thereby allows researchers to judge a DCE's quality and generalizability.

Keywords: discrete choice experiment, mixed-methods, patient preferences, rheumatoid arthritis, disease-modifying antirheumatic drugs

\section{Introduction}

Treatment of rheumatoid arthritis (RA) rests primarily on the long-term use of disease-modifying antirheumatic drugs (DMARDs). It is recommended to start DMARD therapy as soon as possible after the diagnosis is confirmed. ${ }^{1,2}$ Early initiation enables optimal control of disease progression, reduces radiological damage and
Correspondence: Elke GE Mathijsse Maartenskliniek, PO Box 9011 , Nijmegen, the Netherlands

$\mathrm{Tel}+3$ I 243659185

Email e.mathijssen@maartenskliniek.nl 
improves patients' functioning and prognosis. ${ }^{3}$ However, the full benefits of DMARDs are often not realized because many patients are non-adherent (ie, they do not take their medication as prescribed). Empirical studies showed adherence rates varying from $30 \%$ to $80 \%{ }^{4}$ Non-adherence contributes to poor clinical outcomes and increased healthcare utilization and costs. ${ }^{5}$ Patient preferences play an important role in adherence. Patients are more likely to be satisfied with and adhere to a treatment that is in line with their preferences. ${ }^{4,6}$ Therefore, along with clinical guidelines, preferences of patients with RA should provide direction in making choices regarding DMARD therapy. ${ }^{1,2}$

Discrete choice experiments (DCEs) are increasingly used to elicit patient preferences. ${ }^{7}$ They are based on the assumption that a treatment can be described by its characteristics, also referred to as attributes (eg, for medication: route of administration). Attributes in turn are specified by several levels (eg, for route of administration: oral, subcutaneous and intravenous). DCEs are typically implemented in surveys consisting of a series of choice tasks. ${ }^{8-11}$ A choice task consists of two or more realistic, but hypothetical, treatments between which patients are asked to choose. Treatments are described by a number of attributes and each attribute takes one of several levels. Patients' choices provide information on the relative importance of the attributes and the trade-offs that they are willing to make between them. Furthermore, the exact influence of each level on their choices can be quantified through statistical modeling. ${ }^{12}$

In recent years, several studies have used a DCE to elicit preferences of patients with RA regarding DMARDs. ${ }^{13-16}$ These studies reported extremely briefly on the development of attributes and levels. They only described the methods that were used to identify attributes and levels (eg, a literature review, interviews, and focus groups). Detailed information about search strings, eligibility criteria, interview guides and so forth were lacking. The development of attributes and levels is, however, a fundamentally important process. The validity of a DCE largely depends on the researchers' ability to specify relevant attributes and levels. ${ }^{8-10,17}$ Due to the brevity of reporting in previous research, it is unclear whether the development of attributes and levels is conducted rigorously. ${ }^{18}$ A comprehensive description of this process ensures transparency and thereby allows researchers to judge a DCE's quality and generalizability. ${ }^{18}$ It also provides a reference point for future studies. Therefore, the aim of this study was to comprehensively describe the identification, refinement, and selection of attributes and levels for a DCE on preferences of patients with RA regarding DMARDs.

\section{Methods}

A variety of methods are being used to develop attributes and levels for a DCE, including a literature review, expert recommendations, existing health outcome measures, surveys, interviews, and focus groups..$^{17,18}$ The use of qualitative methods, before, alongside or after other methods, is highly recommended by experts in the field. ${ }^{8-10,18,19}$ Qualitative methods have the particular advantage of allowing researchers to draw on the views of future respondents. This minimizes the potential for misspecification of attributes and levels through overreliance on the researchers' own views. ${ }^{18}$ In this study, a mixed-method approach was used. It consisted of three consecutive steps: 1) a literature review; 2) expert recommendations; and 3) focus groups.

\section{Step I:A literature review}

A scoping review was performed to rapidly examine the extent, range and nature of research activity. ${ }^{20}$ The framework of Arksey and O'Malley ${ }^{20}$ was followed. This framework provides a comprehensive foundation for scoping review methodology and comprises five stages: 1) identifying the research question; 2) identifying relevant studies; 3) study selection; 4) charting the data; and 5) collating, summarizing and reporting the results. ${ }^{20}$

\section{Identifying the research question}

The following research question was identified: What attributes and levels of DMARDs, used to treat RA, can be identified from the literature?

\section{Identifying relevant studies}

The databases of PubMed, Embase and CINAHL were searched from inception to October 2016, using both Medical Subject Headings (MeSH) terms and free text words. There were no restrictions on study designs. Only publications written in English were included. Table 1 shows the search strings that were used.

\section{Study selection}

After combining the search results from the three databases, duplicates were removed. The remaining publications were screened for inclusion on two levels. The first level concerned a screening on title and abstract and the second level a screening of the full texts. The inclusion criteria were: 1) studies on adult (ie, aged 18 years or older) patients with RA; and 2) studies on attributes of DMARDs, preferences for DMARDs or experiences with DMARDs. Two researchers (EM and MV) independently screened the publications on title and abstract. The full texts of the publications that met the inclusion criteria were obtained and independently screened by the same researchers. The publications were excluded if they did not meet the inclusion criteria. 
Table I Search strings

\begin{tabular}{|c|c|c|}
\hline PubMed & CINAHL & Embase \\
\hline (Rheumatoid arthritis [MeSH] OR & (MH “Arthritis, Rheumatoid+” OR & exp Rheumatoid arthritis/ OR Rheumatoid \\
\hline Rheumatoid arthritis) & Rheumatoid arthritis) & arthritis.mp. \\
\hline AND & AND & AND \\
\hline (Antirheumatic agents [MeSH] OR & (MH “Antirheumatic Agents+” OR & $\exp$ Antirheumatic agent/ OR Antirheumatic \\
\hline Antirheumatic agents OR DMARDs OR & antirheumatic agents OR DMARDs OR & agents.mp. OR DMARDs.mp. OR \\
\hline DMARD OR Azathioprine OR Methotrexate & DMARD OR Azathioprine OR Methotrexate & DMARD.mp. OR Methotrexate.mp. OR \\
\hline OR Sulfasalazine OR Hydroxychloroquine & OR Sulfasalazine OR Hydroxychloroquine & Azathioprine.mp. OR Sulfasalazine.mp. OR \\
\hline OR Auranofin OR Leflunomide OR & OR Auranofin OR Leflunomide OR & Hydroxychloroquine.mp. OR Auranofin.mp. \\
\hline Etanercept OR Adalimumab OR Golimumab & Etanercept OR Adalimumab OR Golimumab & OR Leflunomide.mp. OR Etanercept.mp. OR \\
\hline OR Infliximab OR Certolizumab OR & OR Infliximab OR Certolizumab OR & Adalimumab.mp. OR Golimumab.mp. OR \\
\hline Abatacept OR Tocilizumab OR Rituximab) & Abatacept OR Tocilizumab OR Rituximab) & Infliximab.mp. OR Certolizumab.mp. \\
\hline AND & AND & OR Abatacept.mp. OR Tocilizumab.mp. \\
\hline \multirow[t]{4}{*}{ (preferences OR attributes OR experiences) } & (preferences OR attributes OR experiences) & OR Rituximab.mp. \\
\hline & & AND \\
\hline & & preferences.mp. OR attributes.mp. \\
\hline & & OR experiences.mp. \\
\hline
\end{tabular}

Abbreviations: DMARD, disease-modifying antirheumatic drug; MeSH, Medical Subject Headings.

In case of disagreement a third researcher (LvD) was decisive in including or excluding the publications.

\section{Charting the data and collating, summarizing and reporting the results}

For each of the included publications data were charted: author(s) (year of publication), objective(s), study design, study population and sample size, attributes (levels), and conclusion. This was done by three researchers (EM, MV and $\mathrm{MvH}$ ). Each researcher charted a part of the data. Based on the data chart, attributes and levels were identified and the researchers jointly compiled a list.

\section{Step 2: Expert recommendations}

The list of attributes and levels was evaluated by an expert panel. A purposive sampling approach was used to recruit two rheumatologists, two pharmacists, two rheumatology nurses or nurse practitioners, two researchers, and two patients with RA. The experts were not in any other way involved in this study. The list was sent to them by email and provided with a brief instruction. The experts were instructed to independently comment on the relevance of the attributes and levels. Also, they were encouraged to add new attributes and levels to the list. Their recommendations were processed by the researchers. This resulted in a more comprehensive list that was used to inform the focus groups.

\section{Step 3: Focus groups}

\section{Patient recruitment}

Patients were recruited from the outpatient pharmacy of the Sint Maartenskliniek in Nijmegen, the Netherlands and the local rheumatology patient association in "s-Hertogenbosch, the Netherlands. A convenience sampling approach was used. Eligibility criteria were: 1) a diagnosis of RA, confirmed by a rheumatologist; 2) aged 18 years or older; and 3) proficiency in the Dutch language. An invitation letter and informed consent form were sent to eligible patients. Personal experiences of the researchers with this recruitment technique (ie, impersonal invitations for focus groups on predetermined dates and times) showed response rates of $5 \%-10 \%$. Therefore, a group of 400 patients was invited.

\section{Data collection}

The focus groups were facilitated by an independent, experienced moderator $(\mathrm{AH})$ and an assistant moderator (EM). A discussion guide, including engagement, exploratory and exit questions, was used to standardize and structure the data collection (Figure S1). ${ }^{21}$ All focus groups were audio recorded and subsequently transcribed verbatim by a professional transcription service. Before the start of the focus groups, each patient completed a brief questionnaire on socio-demographic and clinical characteristics, including age, gender, educational level, employment status, disease duration, and current DMARD use.

The focus groups were divided into two parts. First, the patients individually wrote down attributes and levels of DMARDs that were important to them in making choices regarding DMARD therapy. This was followed by a group discussion. Second, a ranking exercise was performed to scale down the number of attributes to a number manageable within a DCE. There is no consensus in the literature on what counts as a manageable number. Reviews showed that, in practice, most DCEs included a number of attributes between 
four and seven. ${ }^{11,22}$ The list of attributes and levels derived from the literature review and expert recommendations was presented to the patients. They were asked to individually rank the attributes by relevance. Rank one represented the most relevant attribute. Attributes that were newly identified during the first part of the focus group could also be ranked. A group discussion on the patients' individual rankings and the wording of the attributes and levels was held afterwards.

\section{Data analysis}

The patients' individual rankings were summed to derive a ranking at group level and make an a priori selection of the most relevant attributes. The transcripts were analyzed using a thematic analysis method. ${ }^{23}$ This was done independently by two researchers ( $\mathrm{MvH}$ and $\mathrm{SZ})$. Both a deductive and inductive approach were used. The codes and themes were pre-selected based on the list of attributes and levels. The inductive approach led to a revision of the pre-selected codes and themes. Additionally, new ones were identified. The inductive approach also made it possible for the researchers to gain a deeper insight into the relevance of the attributes and levels from the view of patients with RA. The software program MAXQDA 10 was used for the qualitative analysis. It was checked whether data saturation occurred. This was defined as the point where no new codes and themes were identified. ${ }^{24}$ Also, a member check was performed. A summary of the discussions was sent to the patients by email and they were asked to comment on its accuracy. Eventually, the results of the ranking exercise and qualitative analysis were extensively discussed by the researchers and decisions on the selection of attributes and levels in the DCE were jointly made. Two rheumatologists, who were not involved in the expert panel, were consulted for recommendations regarding the range of the levels.

\section{Pilot test}

A series of choice tasks for the DCE were composed, using the selected attributes and levels. The choice tasks were implemented in a survey. Eleven patients with RA were invited to complete the survey. They were members of a local panel for patient participation in research. An invitation was sent to them by email and included a link to the survey. Also, a corresponding, open-ended questionnaire was attached (Box S1). Their understanding of the attributes and levels was reviewed. They were also asked to comment on the wording of the attributes and levels. Next to that, the pilot test reviewed the acceptability of the number of attributes and levels and total length of the survey.

\section{Ethical considerations}

The medical research ethical committee (MREC) of ArnhemNijmegen, the Netherlands, waived ethical approval since the study was not subject to the medical research involving human subjects act (file number: 2016-2474). All patients signed informed consent for participation in the focus groups. Patient data were handled according to the applicable laws and regulations. Personal identifying information was replaced by study codes. A document that linked the study codes to the patients' identifying information was digitally stored and protected.

\section{Results}

This study's mixed-methods approach consisted of three consecutive steps. In order to portray the whole process, the results are described step by step.

\section{Step I:A literature review}

The search generated 884 publications (PubMed: $n=262$; Embase: $n=481$; and CINAHL: $n=141)$. After removing duplicates $(n=232), 652$ publications remained. The firstlevel screening on title and abstract led to the exclusion of 611 publications. Twenty-eight more publications were excluded after the second-level screening of the full texts: 14 publications were conference abstracts, 11 publications did not meet the inclusion criteria, two publications were not written in English and one publication turned out to be a previously overlooked duplicate. In total, 13 publications, representing 13 unique studies, were included. ${ }^{13-15,25-34}$ Figure 1 shows the flowchart of the selection process.

Data were charted for each of the included publications (Table S1). Based on the data chart, 19 attributes were identified. Each attribute was specified by two to seven levels. Table 2 shows the list of attributes and levels that resulted after the literature review.

\section{Step 2: Expert recommendations}

The evaluation of the experts resulted in the removal of one attribute (improvement in daily functioning). This attribute was specified by the levels " $45 \%$ of the patients feel much better", " $60 \%$ of the patients feel much better", and " $75 \%$ of the patients feel much better". It was considered not specific enough and therefore likely to give rise to ambiguities. Two new attributes were identified: "required storage conditions" and "chance of injection side reaction". Regarding the attribute "frequency of administration" one new level (once every 12 weeks) was identified. One new level (at the general practice) was also identified regarding the attribute "location 


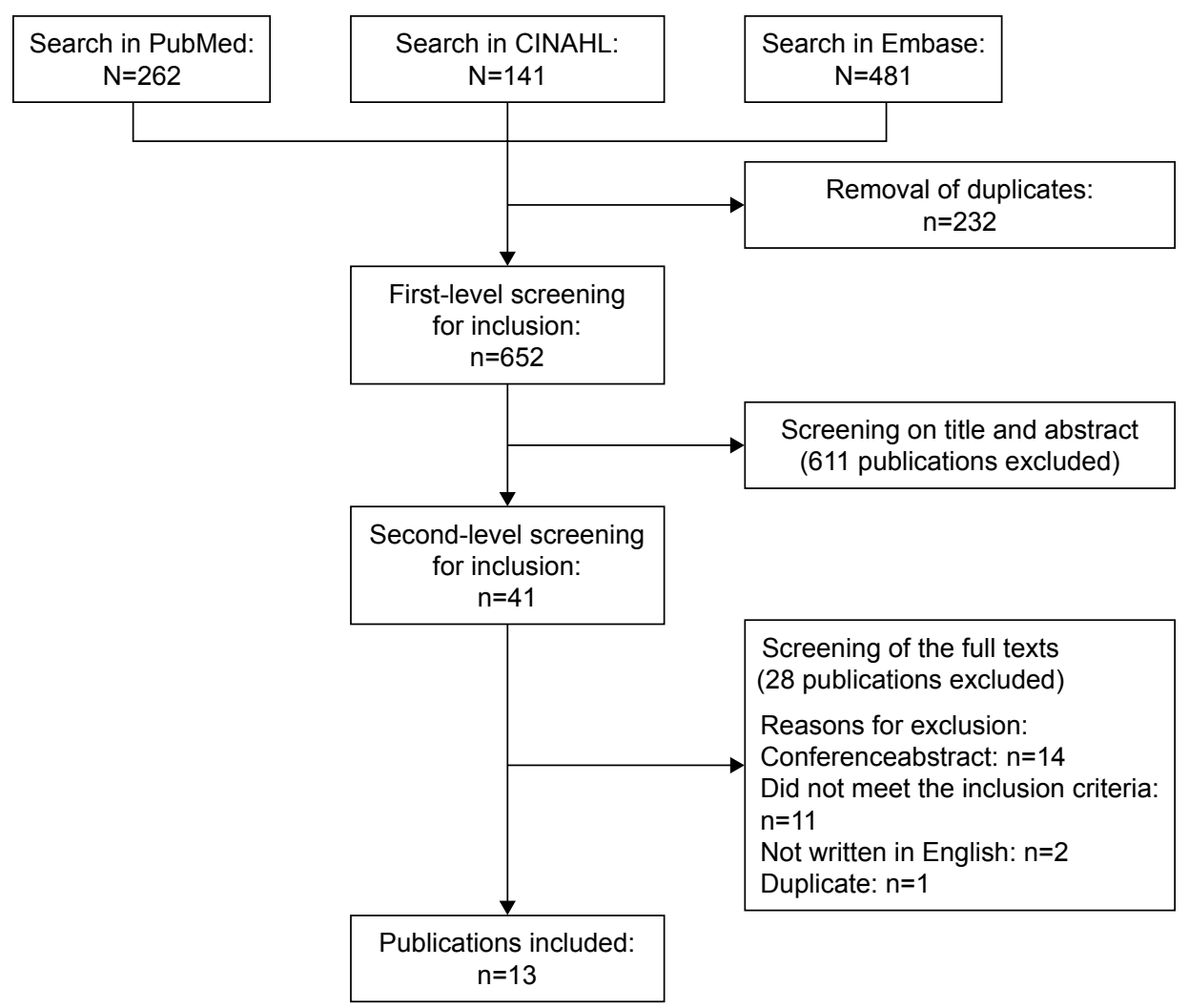

Figure I Flowchart selection process.

of administration". Furthermore, the scope of two attributes "experience with DMARD" and "risk of dizziness, nausea, vomiting or diarrhea" was considered too broad. These attributes were split into two. The first was split into "years of experience with DMARD to treat RA" and "knowledge about long-term consequences of DMARD use" and the second was split into "risk of headache or dizziness" and "risk of gastrointestinal complications". The result after the expert recommendations was a more comprehensive list of 22 attributes, each specified by two to eight levels.

\section{Step 3: Focus groups}

Three focus groups including 23 patients with RA were conducted. The focus groups lasted between 90 and 120 minutes. Table 3 shows the socio-demographic and clinical characteristics of the patients.

\section{Identification}

The patients in the first and second focus group did not identify new attributes and levels. One new attribute (contraindicated during pregnancy and breast feeding) was identified during the third focus group. This attribute was also ranked. The highest ranked, and thus most relevant attributes at group level, were: 1) risk of cancer; 2) risk of liver injury;
3) chance of efficacy; 4) risk of joint damage; 5) onset of action; 6) risk of serious infections; and 7) knowledge about long-term consequences of DMARD use. "Costs" was the lowest ranked attribute. Table S2 includes the patients' ranking. The group discussions mainly focused on the relevance of the attributes "route of administration" and "frequency of administration". Also, the patients expressed their preferences for DMARDs with a low risk of side effects. Adjustments to the wording of the attributes and levels were not deemed necessary.

\section{Refinement and selection}

Based on the literature, the researchers decided to include seven attributes in the DCE. ${ }^{11,22}$ The refinement and selection of the attributes and levels required some difficult decisions. The attributes "route of administration" and "frequency of administration" were not highly ranked. The results of the qualitative analysis, however, revealed that these attributes were relevant from the view of patients with RA. Indeed, the group discussions mainly focused on their relevance. It was therefore decided to include them anyway. The attributes "risk of joint damage" and "knowledge about long-term consequences of DMARD use" were highly ranked. Yet, it was decided not to include these attributes. The first was 
Table 2 List with attributes and levels

\begin{tabular}{|c|c|}
\hline Attribute & Levels \\
\hline \multirow[t]{2}{*}{ Combination therapy } & Yes \\
\hline & No \\
\hline \multirow[t]{3}{*}{ Route of administration } & Oral \\
\hline & Subcutaneous \\
\hline & Intravenous \\
\hline \multirow[t]{2}{*}{ Location of administration } & At home \\
\hline & At the hospital \\
\hline \multirow[t]{2}{*}{ Preparation of DMARD needed } & Yes \\
\hline & No \\
\hline \multirow[t]{7}{*}{ Frequency of administration } & Daily \\
\hline & Twice a day \\
\hline & Weekly \\
\hline & Every 2 weeks \\
\hline & Every 4 weeks \\
\hline & Every 8 weeks \\
\hline & Every 6 months \\
\hline \multirow[t]{4}{*}{ Time needed for infusion } & 30 minutes \\
\hline & 60 minutes \\
\hline & 120 minutes \\
\hline & 240 minutes \\
\hline \multirow[t]{3}{*}{ Experience with DMARD } & More than 20 years of experience \\
\hline & New DMARD with unknown \\
\hline & long-term consequences \\
\hline \multirow[t]{3}{*}{ Chance of efficacy } & $40 \%$ \\
\hline & $60 \%$ \\
\hline & $75 \%$ \\
\hline \multirow[t]{5}{*}{ Onset of action } & I week \\
\hline & 2 weeks \\
\hline & 4 weeks \\
\hline & 6 weeks \\
\hline & 8 weeks \\
\hline \multirow[t]{3}{*}{ Improvement in daily functioning } & $45 \%$ of the patients feel much better \\
\hline & $60 \%$ of the patients feel much better \\
\hline & $75 \%$ of the patients feel much better \\
\hline \multirow[t]{4}{*}{ Risk of joint damage } & $60 \%$ of the patients develops no joint \\
\hline & damage within I year \\
\hline & $75 \%$ of the patients develops no joint \\
\hline & damage within I year \\
\hline \multirow[t]{2}{*}{ Risk of cancer } & No increased risk \\
\hline & $0.1 \%$ increased risk \\
\hline \multirow[t]{2}{*}{ Risk of serious infections } & I\% increased risk \\
\hline & $5 \%$ increased risk \\
\hline \multirow[t]{3}{*}{ Risk of liver injury } & No increased risk \\
\hline & $0.1 \%$ increased risk \\
\hline & I\% increased risk \\
\hline \multirow[t]{2}{*}{ Risk of hair loss } & No increased risk \\
\hline & $10 \%$ increased risk \\
\hline \multirow{3}{*}{$\begin{array}{l}\text { Risk of dizziness, nausea, } \\
\text { vomiting or diarrhea }\end{array}$} & No increased risk \\
\hline & $10 \%$ increased risk \\
\hline & $30 \%$ increased risk \\
\hline \multirow[t]{2}{*}{ Risk of mouth ulcers } & No increased risk \\
\hline & $10 \%$ increased risk \\
\hline \multirow[t]{3}{*}{ Risk of skin rash } & No increased risk \\
\hline & $10 \%$ increased risk \\
\hline & $40 \%$ increased risk \\
\hline
\end{tabular}

(Continued)
Table 2 (Continued)

\begin{tabular}{ll}
\hline Attribute & Levels \\
\hline Costs & $500-1,000$ euros per patient \\
& per year \\
& $1,000-10,000$ euros per patient \\
& per year \\
& $10,000-15,000$ euros per patient \\
& per year \\
\hline
\end{tabular}

Abbreviation: DMARD, disease-modifying antirheumatic drug.

considered to be dependent on the attribute "chance of efficacy". The second was considered not specific enough since it was unclear how many years were meant by longterm. The researchers acted upon the consulted rheumatologists' recommendations to include realistic levels. On the one hand, the range of levels had to be wide enough to induce trading behavior. On the other hand, however, levels had to be realistic in order to obtain clinically meaningful results. ${ }^{7}$

The results of the ranking exercise and qualitative analysis led to the refinement and selection of the following attributes: 1) route of administration; 2) frequency of administration; 3) chance of efficacy; 4) onset of action; 5) risk of serious infections; 6) risk of liver injury; and 7) risk of cancer. Each attribute was specified by three levels. Table 4 shows the attributes and levels that were eventually included in the DCE. Quotes from the transcripts of the focus groups were included in Table 4 to prove that decisions on the inclusion of attributes and levels were rooted in the patients' voices.

\section{Pilot test}

The survey and corresponding questionnaire were completed by five patients with RA. They had no difficulties in understanding the attributes and levels. The wording of the attributes and levels was also considered appropriate. The patients only noticed some minor typos that were corrected by the researchers. The pilot test revealed that both the number of attributes and total length of the survey were acceptable. All patients completed the survey in 15 to 20 minutes. Apart from the correction of typos, no adjustments were made to the attributes and levels.

\section{Discussion}

In contrast to previous studies, this study comprehensively described the identification, refinement, and selection of attributes and levels for a DCE on preferences of patients with RA regarding DMARDs. The attributes and levels were developed using a mixed-method approach, consisting of three consecutive steps. A list of attributes and levels 
Table 3 Socio-demographic and clinical characteristics of the patients

\begin{tabular}{|c|c|c|c|c|}
\hline Characteristic & $\begin{array}{l}\text { Group I } \\
(\mathrm{N}=8)\end{array}$ & $\begin{array}{l}\text { Group } 2 \\
(\mathrm{~N}=\mathrm{II})\end{array}$ & $\begin{array}{l}\text { Group } 3 \\
(N=4)\end{array}$ & $\begin{array}{l}\text { Total } \\
(\mathrm{N}=23)\end{array}$ \\
\hline Age in years (median (range)) & $57(52-78)$ & $62(38-78)$ & $62.5(36-68)$ & $62(36-78)$ \\
\hline \multicolumn{5}{|l|}{ Gender (\%) } \\
\hline Male & 0 & 18 & 25 & 13 \\
\hline Female & 100 & 82 & 75 & 87 \\
\hline \multicolumn{5}{|l|}{ Educational level ${ }^{a}(\%)$} \\
\hline Low & 38 & 73 & 0 & 48 \\
\hline Medium & 25 & 27 & 50 & 30 \\
\hline High & 38 & 0 & 50 & 22 \\
\hline \multicolumn{5}{|l|}{ Employment status (\%) } \\
\hline Employed & 50 & 18 & 0 & 26 \\
\hline Unemployed & 50 & 82 & 100 & 74 \\
\hline Disease duration in years (median (range)) & $7(2-25)$ & $8(2-42)$ & $16(12-22)$ & II (2-42) \\
\hline \multicolumn{5}{|l|}{ Current DMARD use (\%) } \\
\hline sDMARD, methotrexate & 50 & 27 & 75 & 44 \\
\hline sDMARD, other ${ }^{b}$ & 38 & 36 & 0 & 30 \\
\hline bDMARD, anti-TNF & 50 & 46 & 50 & 48 \\
\hline bDMARD, other ${ }^{c}$ & 13 & 18 & 25 & 17 \\
\hline
\end{tabular}

Notes: a Level of education: low = up to and including lower technical and vocational training; medium = up to and including secondary technical and vocational training; high = up to and including higher vocational training and university. bsDMARD, other: Hydroxychloroquine and Sulfasalazine. "bDMARD, other: Rituximab and Tocilizumab. Abbreviations: DMARD, disease-modifying antirheumatic drug; TNF, tumor necrosis factor.

was derived from the first two steps (ie, a literature review and expert recommendations) and used to inform the focus groups in the third step. Eventually, these steps resulted in the selection of seven attributes, each specified by three levels.
A pilot test confirmed the appropriateness of the attributes and levels for inclusion in the DCE.

The following attributes were included: 1) route of administration; 2) frequency of administration; 3) chance

Table 4 Included attributes and levels

\begin{tabular}{|c|c|c|}
\hline Attribute & Levels & Quotes \\
\hline Route of administration & $\begin{array}{l}\text { Oral } \\
\text { Subcutaneous } \\
\text { Intravenous }\end{array}$ & $\begin{array}{l}\text { - "I'd rather have pills than injections." (Patient I03, female, } 55 \text { years) } \\
\text { "They did offer to put me on the drip once, but I do not want that. I want to be } \\
\text { in control myself. [...] If I do the injections myself I still have the idea of being in } \\
\text { control." (Patient 203, female, } 52 \text { years) }\end{array}$ \\
\hline Frequency of administration & $\begin{array}{l}\text { Daily } \\
\text { Weekly } \\
\text { Monthly }\end{array}$ & $\begin{array}{l}\text { - "I would not want to be on the drip too often, as it takes up a lot of time." } \\
\text { (Patient } 30 \text { I, female, } 36 \text { years) } \\
\text { - "[...] and then you have to take all those stupid pills in between. They determine } \\
\text { your day. I cannot really cope with that." (Patient 202, female, } 45 \text { years) } \\
\text { - "Taking something on a daily basis would not be acceptable to me. Then you're } \\
\text { always busy with your medicines." (Patient } 207, \text { female, } 67 \text { years) }\end{array}$ \\
\hline Chance of efficacy & $\begin{array}{l}40 \% \\
60 \% \\
80 \%\end{array}$ & $\begin{array}{l}\text { - "Well, I think it is important that the medicine works for me. That's the main } \\
\text { thing." (Patient 205, male, } 60 \text { years) } \\
\text { - "It should work. I do not want to be ill. Period." (Patient I06, female, } 62 \text { years) }\end{array}$ \\
\hline Onset of action & $\begin{array}{l}\text { I week } \\
6 \text { weeks } \\
12 \text { weeks }\end{array}$ & $\begin{array}{l}\text { "How long it takes for the medicine to work. As soon as possible, as far as I'm } \\
\text { concerned." (Patient I08, female, } 73 \text { years) }\end{array}$ \\
\hline Risk of serious infections & $\begin{array}{l}\text { No increased risk } \\
0.5 \% \text { increased risk } \\
1 \% \text { increased risk }\end{array}$ & $\begin{array}{l}\text { - "I have used a biological for } 3 \text { months. But it didn't work for me so I was } \\
\text { allowed to stop using it. I was so frightened when I read about things like } \\
\text { infections. Then I thought: oh no! Actually ... I was happy when I could stop } \\
\text { using it." (Patient 303, female, } 62 \text { years) }\end{array}$ \\
\hline Risk of liver injury & $\begin{array}{l}\text { No increased risk } \\
0.1 \% \text { increased risk } \\
1 \% \text { increased risk }\end{array}$ & $\begin{array}{l}\text { - "To me, my health is my greatest wealth. [...], the risk of kidney or liver injury. } \\
{[\ldots] \text { These are things that matter to me." (Patient 203, female, } 52 \text { years) }}\end{array}$ \\
\hline Risk of cancer & $\begin{array}{l}\text { No increased risk } \\
0.1 \% \text { increased risk } \\
0.5 \% \text { increased risk }\end{array}$ & $\begin{array}{l}\text { - "What else do I find important? The risk of cancer. [...] I am very frightened of } \\
\text { that, cancer." (Patient } 2 \text { II, female, } 78 \text { years) }\end{array}$ \\
\hline
\end{tabular}


of efficacy; 4) onset of action; 5) risk of serious infections; 6) risk of liver injury; and 7) risk of cancer. The attributes "route of administration" and "frequency of administration" were also included in all previous studies. ${ }^{13-16}$ This study confirmed that these attributes are highly relevant when considering attributes for inclusion in comparable DCEs. During the focus groups, preferences for DMARDs with a low risk of side effects were expressed by the patients. Comparable DCEs should therefore be considered to include attributes referring to side effects. Side effects differ in severity. It is important to realize that severity is a subjective term. What is severe to one person may not necessarily be severe to another. In order to avoid ambiguous interpretations one should not use such subjective terms (eg, risk of severe side effects). Whereas one previous study also included the attribute "costs", ${ }^{13}$ this study showed its irrelevance for inclusion in the DCE. This may be explained by the fact that, in the Netherlands, DMARD therapy is covered by health insurance. There are no out-of-pocket costs involved for patients. Obviously, this attribute is context-specific and not easily generalizable.

It is clear that the included attributes are important to patients with RA in making choices regarding DMARD therapy. Research has shown that there is an association between a decision making process in which healthcare providers take account of what is important to patients and higher treatment satisfaction. ${ }^{4,6}$ Treatment satisfaction in turn is associated with improved adherence. ${ }^{35}$ Patients are more likely to adhere to a treatment they are satisfied with. In clinical practice, it is therefore worthwhile paying attention to the included attributes when aiming to improve adherence. Healthcare providers should take them into account in the decision making process. The DCE will eventually provide insight into the relative importance of the included attributes.

This study's mixed-methods approach has been found highly suitable to identify, refine and select attributes and levels for a DCE. The benefits of several methods (ie, a literature review, expert recommendations, and focus groups) were utilized. A list of attributes and levels was derived from the literature review and expert recommendations. These two steps allowed a quick identification of attributes and levels. The list also proved to be comprehensive since only one new attribute was identified by the patients in the third focus group. It can therefore be argued that meanwhile there is sufficient literature available to identify attributes and levels of DMARDs, used to treat RA.

It is, however, crucial to use qualitative methods for the refinement and selection of attributes and levels.
Qualitative analysis made it possible for the researchers to gain a deeper insight into the relevance of the attributes and levels from the view of patients with RA. Thus, the potential for misspecification through overreliance on the researchers' own views was minimized. In this study, decisions on the inclusion of attributes and levels were rooted in the patients' voices (Table 4). Moreover, attributes and levels should be clearly described and explained where needed since they are frequently misunderstood. ${ }^{18}$ During the focus groups, the patients commented on the wording of the attributes and levels. This resulted in the inclusion of attributes and levels that are understandable to the DCE's target group.

One of the challenges of selecting attributes and levels for inclusion is related to scaling down the often large number of attributes to a number manageable within a DCE. Although there is no fixed threshold number, the number of attributes is usually limited to ten. ${ }^{11,22}$ Beyond that, the choice tasks will get too complex. Hiligsmann et al used a nominal group technique to identify the most relevant attributes for inclusion. ${ }^{36}$ They suggested that the use of a simple ranking exercise, such as the one in this study, may also be sufficient for this purpose. Abiiro et al also suggested to use simple quantitative tools for this purpose. ${ }^{37}$ However, they stated that qualitative reasoning would still be required to guarantee relevant attributes and levels. Their statement was supported by this study. The attribute "frequency of administration", for example, was not highly ranked. Nevertheless, it was included anyway based on the results of the qualitative analysis.

Several strengths and limitations of this study deserve attention. A strength was its mixed-methods approach. The methods that were used in this study have different pros and cons and complemented each other. The analysis of the qualitative data (ie, transcripts) was another strength. Researchers triangulation led to a broader and deeper understanding of the data. Moreover, bias was limited because of incorporating control on each other's interpretations. The literature search was limited to the databases of PubMed, Embase and CINAHL. Relevant studies indexed only in other databases (eg, PsycINFO) may have been missed. However, this study has shown that the vast majority of attributes and levels were identified by the scoping review. It is unlikely that other studies, although relevant, would have resulted in the identification of new attributes and levels. Additionally, DMARDs not licensed in Europe at the time of the literature search, such as tofacitinib, were not included as search terms. This has not affected the validity of the results since studies investigating these DMARDs were still 
found by other search terms. These DMARDs also do not have attributes and levels that differ from the ones that were identified in this study. When using qualitative methods, Coast et al recommended an iterative process between data collection and analysis. ${ }^{18}$ In this study, the data were collected in advance and then analyzed. This was a limitation. However, it was checked whether data saturation occurred. If this had not been the case, additional focus groups would have been conducted. Another limitation is the convenience sampling approach that was used to recruit patients for the focus groups. According to Coast et al, the potential for misspecification of attributes and levels always exists, even when qualitative methods are used. ${ }^{18}$ It is therefore recommended to use a purposive sampling approach in order to obtain a full range of views. Nevertheless, the patients in this study turned out to represent a mix of socio-demographic and clinical characteristics.

\section{Conclusion}

In this study, recently recommended methods to identify, refine, and select attributes and levels for a DCE were used and comprehensively described. Moreover, the suitability of a mixed-methods approach was highlighted. This study contributes to the limited literature on the development of attributes and levels for a DCE. Future research should pay more attention to a comprehensive description of this process. This ensures transparency and thereby allows researchers to judge a DCE's quality and generalizability.

\section{Acknowledgments}

The authors would like to acknowledge Annette Heinen for facilitating the focus groups as a moderator and Peter van Grinsven and Manorma Dwarkasing for participating as patient representatives in this study.

This study was supported by funding from Pfizer Incorporated. The funding agreement ensured the authors' independence in designing the study, interpreting the data, writing, and publishing the report.

\section{Disclosure}

The authors report no conflicts of interest in this work.

\section{References}

1. Singh JA, Saag KG, Bridges SL Jr, et al. American college of rheumatology guideline for the treatment of rheumatoid arthritis. Arthritis Rheumatol. 2015;2016(68):1-26.

2. Smolen JS, Landewé R, Bijlsma J, et al. EULAR recommendations for the management of rheumatoid arthritis with synthetic and biological disease-modifying antirheumatic drugs: 2016 update. Ann Rheum Dis. 2017;76(6):960-977.
3. Emery P. Evidence supporting the benefit of early intervention in rheumatoid arthritis. J Rheumatol Suppl. 2002;66:3-8.

4. van den Bemt BJ, Zwikker HE, van den Ende CH. Medication adherence in patients with rheumatoid arthritis: a critical appraisal of the existing literature. Expert Rev Clin Immunol. 2012;8(4):337-351.

5. Osterberg L, Blaschke T. Adherence to medication. $N$ Engl J Med. 2005;353(5):487-497.

6. Barton JL. Patient preferences and satisfaction in the treatment of rheumatoid arthritis with biologic therapy. Patient Prefer Adherence. 2009;3:335-344

7. Mühlbacher A, Johnson FR. Choice experiments to quantify preferences for health and healthcare: state of the practice. Appl Health Econ Health Policy. 2016;14(3):253-266.

8. Louviere J, Swait J, Hensher D. Stated Choice Methods: Analysis and Application. 1st ed. Cambridge: Cambridge University Press; 2000.

9. Lancsar E, Louviere J. Conducting discrete choice experiments to inform healthcare decision making: a user's guide. Pharmacoeconomics. 2008;26(8):661-677.

10. Louviere JJ, Lancsar E. Choice experiments in health: the good, the bad, the ugly and toward a brighter future. Health Econ Policy Law. 2009;4(Pt 4):527-546.

11. de Bekker-Grob EW, Ryan M, Gerard K. Discrete choice experiments in health economics: a review of the literature. Health Econ. 2012;21(2): $145-172$.

12. Hauber AB, González JM, Groothuis-Oudshoorn CG, et al. Statistical methods for the analysis of discrete choice experiments: a report of the ISPOR Conjoint Analysis Good Research Practices Task Force. Value Health. 2016;19(4):300-315.

13. Augustovski F, Beratarrechea A, Irazola V, et al. Patient preferences for biologic agents in rheumatoid arthritis: a discrete-choice experiment. Value Health. 2013;16(2):385-393.

14. Poulos C, Hauber AB, González JM, Turpcu A. Patients' willingness to trade off between the duration and frequency of rheumatoid arthritis treatments. Arthritis Care Res. 2014;66(7):1008-1015.

15. Hazlewood GS, Bombardier C, Tomlinson G, et al. Treatment preferences of patients with early rheumatoid arthritis: a discrete-choice experiment. Rheumatology. 2016;55(11):1959-1968.

16. Alten R, Krüger K, Rellecke J, et al. Examining patient preferences in the treatment of rheumatoid arthritis using a discrete-choice approach. Patient Prefer Adherence. 2016;10:2217-2228.

17. Mangham LJ, Hanson K, Mcpake B, do Hto. How to do (or not to do) ... Designing a discrete choice experiment for application in a low-income country. Health Policy Plan. 2009;24(2):151-158.

18. Coast J, Al-Janabi H, Sutton EJ, et al. Using qualitative methods for attribute development for discrete choice experiments: issues and recommendations. Health Econ. 2012;21(6):730-741.

19. Bridges JF, Hauber AB, Marshall D, et al. Conjoint analysis applications in health - a checklist: a report of the ISPOR Good Research Practices for Conjoint Analysis Task Force. Value Health. 2011;14(4):403-413.

20. Arksey H, O'Malley L. Scoping studies: towards a methodological framework. Int J Soc Res Methodol. 2005;8(1):19-32.

21. Krueger RA. Developing Questions For Focus Groups. 1st ed. Thousand Oaks: CA: Sage publications; 1998.

22. Marshall D, Bridges JF, Hauber B, et al. Conjoint analysis applications in health - how are studies being designed and reported?: an update on current practice in the published literature between 2005 and 2008 . Patient. 2010;3(4):249-256.

23. Braun V, Clarke V. Using thematic analysis in psychology. Qual Res Psychol. 2006;3(2):77-101.

24. Creswell JW. Qualitative Research Design: Quantitative and Mixed Methods Approaches. 3rd ed. Thousand Oaks, CA: Sage Publications; 2009.

25. Fraenkel L, Bogardus ST, Concato J, Felson DT, Wittink DR. Patient preferences for treatment of rheumatoid arthritis. Ann Rheum Dis. 2004;63(11):1372-1378.

26. Chilton F, Collett RA. Treatment choices, preferences and decisionmaking by patients with rheumatoid arthritis. Musculoskeletal Care. 2008;6(1):1-14. 
27. Goekoop-Ruiterman YP, de Vries-Bouwstra JK, Allaart CF, et al. Patient preferences for treatment: report from a randomised comparison of treatment strategies in early rheumatoid arthritis (BeSt trial). Ann Rheum Dis. 2007;66(9):1227-1232.

28. Lisicki R, Chu L. What matters to patients and physicians when considering biologic therapy for rheumatoid arthritis. Postgrad Med. 2008;120(3):154-160.

29. Constantinescu F, Goucher S, Weinstein A, Smith W, Fraenkel L. Understanding why rheumatoid arthritis patient treatment preferences differ by race. Arthritis Rheum. 2009;61(4):413-418.

30. Scarpato S, Antivalle M, Favalli EG, et al. Patient preferences in the choice of anti-TNF therapies in rheumatoid arthritis. Results from a questionnaire survey (RIVIERA study). Rheumatology. 2010;49(2): 289-294.

31. Huynh TK, Ostergaard A, Egsmose C, Madsen OR. Preferences of patients and health professionals for route and frequency of administration of biologic agents in the treatment of rheumatoid arthritis. Patient Prefer Adherence. 2014;8:93-99.

32. Bolge SC, Goren A, Brown D, Ginsberg S, Allen I. Openness to and preference for attributes of biologic therapy prior to initiation among patients with rheumatoid arthritis: patient and rheumatologist perspectives and implications for decision making. Patient Prefer Adherence. 2016;10:1079-1090.
33. Louder AM, Singh A, Saverno K, et al. Patient preferences regarding rheumatoid arthritis therapies: a conjoint analysis. Am Health Drug Benefits. 2016;9(2):84-93.

34. Nolla JM, Rodríguez M, Martin-Mola E, et al. Patients' and rheumatologists' preferences for the attributes of biological agents used in the treatment of rheumatic diseases in Spain. Patient Prefer Adherence. 2016;10: 1101-1113.

35. Barbosa CD, Balp MM, Kulich K, Germain N, Rofail D. A literature review to explore the link between treatment satisfaction and adherence, compliance, and persistence. Patient Prefer Adherence. 2012; 6:39-48.

36. Hiligsmann M, van Durme C, Geusens $P$, et al. Nominal group technique to select attributes for discrete choice experiments: an example for drug treatment choice in osteoporosis. Patient Prefer Adherence. 2013; 7:133-139.

37. Abiiro GA, Leppert G, Mbera GB, Robyn PJ, de Allegri M. Developing attributes and attribute-levels for a discrete choice experiment on micro health insurance in rural Malawi. BMC Health Serv Res. 2014; $14: 235$. 


\section{Supplementary materials}

\begin{tabular}{|c|c|}
\hline Engagement questions & $\begin{array}{l}\text { 1) Could you tell us something about yourself? } \\
\text { For example, what DMARD(s) do you currently use? } \\
\text { This question was asked to the patients in a round robin fashion. }\end{array}$ \\
\hline Exploratory questions & $\begin{array}{l}\text { Part } 1 \\
\text { The definition of attributes and levels (ie, what are attributes and levels?) } \\
\text { was explained to the patients. } \\
\text { 2) What attributes and levels are important to you in making choices } \\
\text { regarding DMARD therapy? Write down what comes to your mind. } \\
\text { The patients could individually write down their answers on a blank paper. } \\
\text { 3) What did you write down? } \\
\text { This question was asked to the patients in a round robin fashion. } \\
\text { All answers were written on a flip chart by the assistant moderator. } \\
\text { 4) What attributes and levels are most important to you? } \\
\text { Pick three from the flip chart and explain your choices. } \\
\text { This question was asked to the patients in a round robin fashion. } \\
\text { The patients' choices were tallied on the flip chart. } \\
\text { 5) Take a look at the flip chart. Have you missed anything? } \\
\text { Part } 2 \\
\text { The list with conceptual attributes and levels derived from the literature } \\
\text { review and expert recommendations was presented to the patients. } \\
\text { 6) Could you rank the attributes by importance? } \\
\text { The patients could individually rank the attributes on a work sheet. } \\
\text { Newly identified attributes could also be ranked. } \\
\text { 7) What are your highest ranked attributes (please explain your answer)? } \\
\text { 8) What are your lowest ranked attributes (please explain your answer)? } \\
\text { 9) What do you think about the wording of the attributes and levels? }\end{array}$ \\
\hline Exit questions & 10) Is there anything else you would like to share with us? \\
\hline
\end{tabular}

Figure SI Discussion guide.

Abbreviation: DMARD, disease-modifying antirheumatic drug.

- How long did it take you to complete the survey?

- What do you think about the length of the survey?

- How difficult was it for you to complete the survey?

- Are the questions in the survey well explained (please explain your answer)?

- Have you missed anything in the survey?

- Do you have any suggestions about how to improve the survey?

Box SI Open-ended questionnaire. 


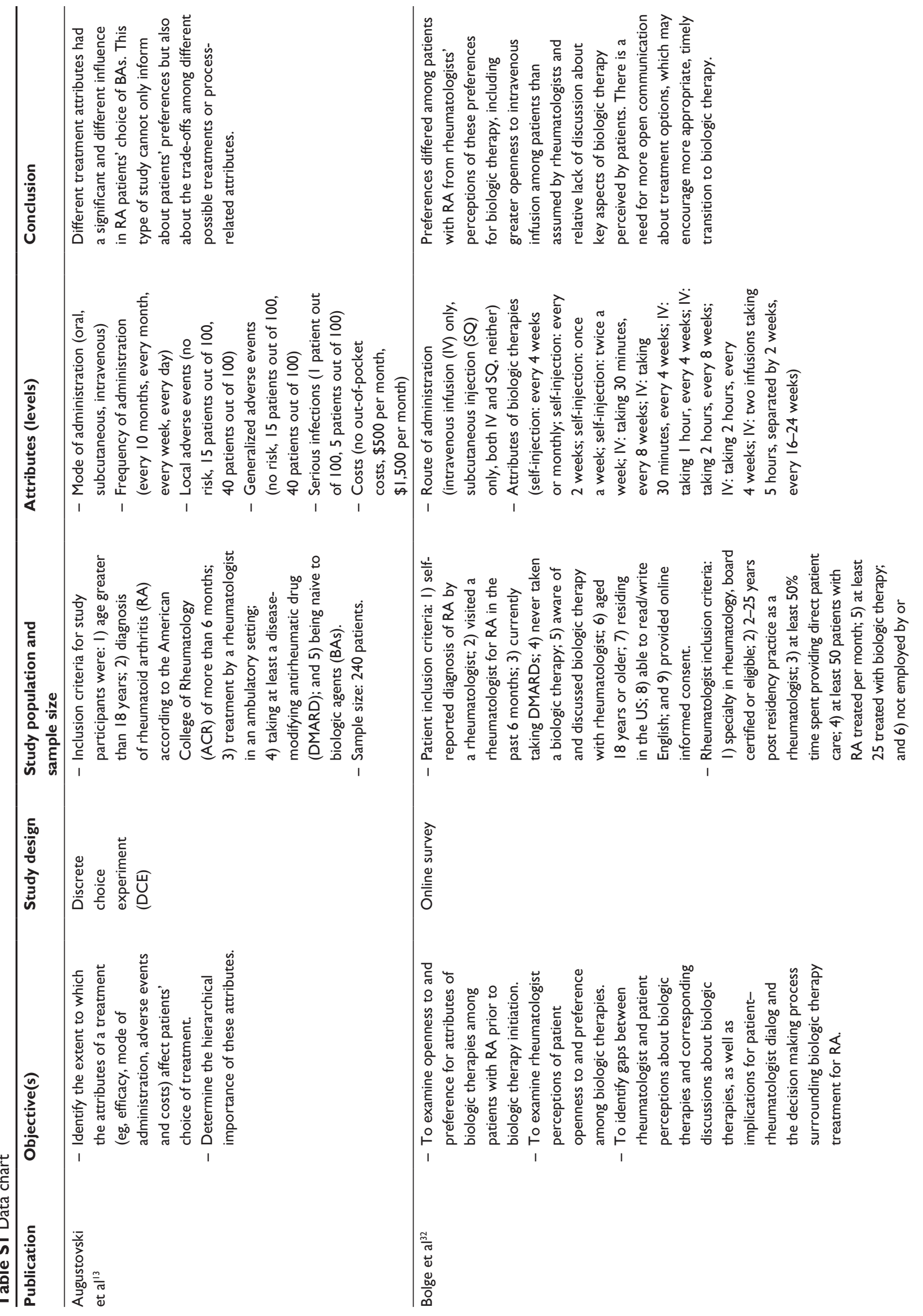




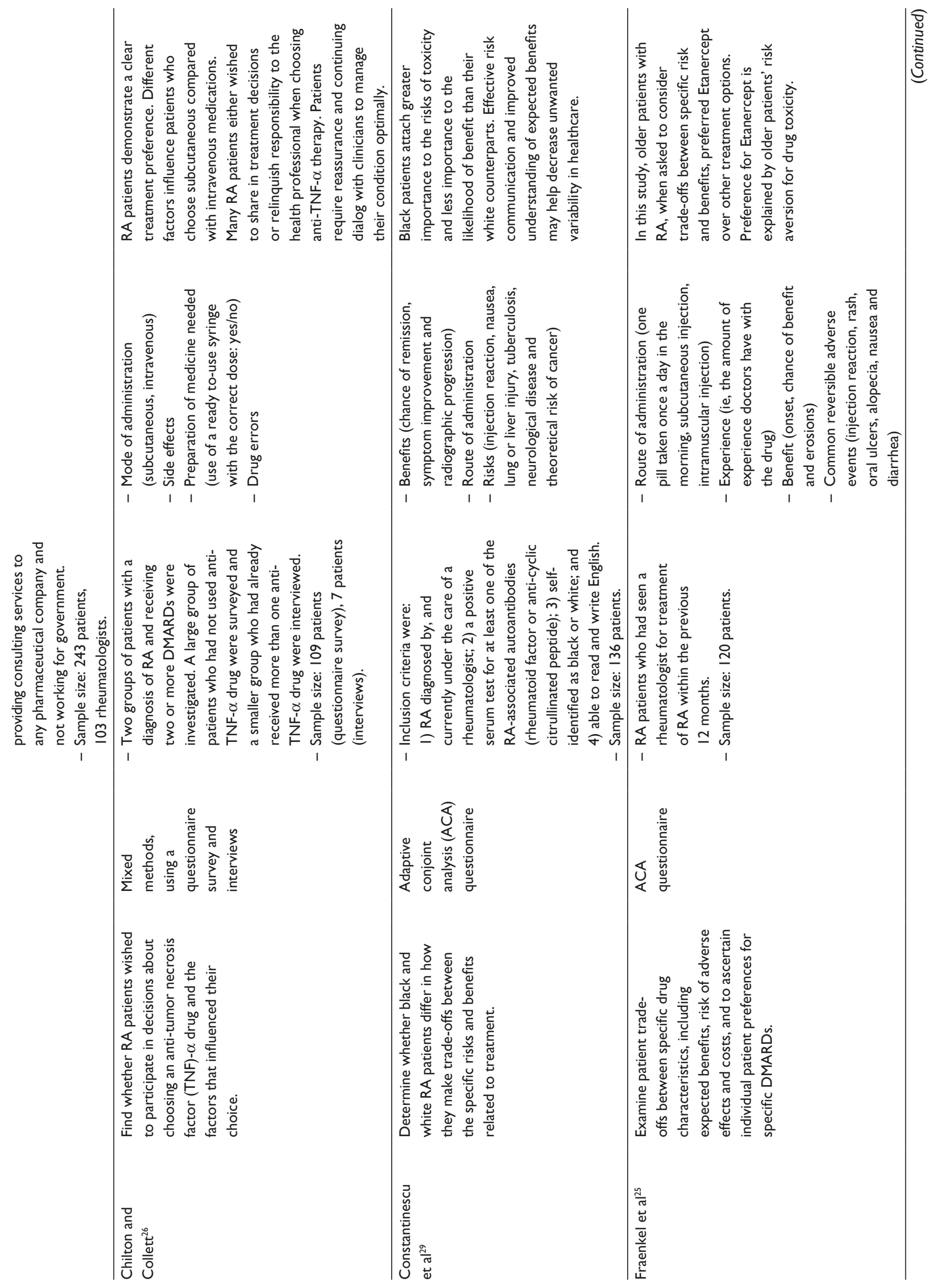




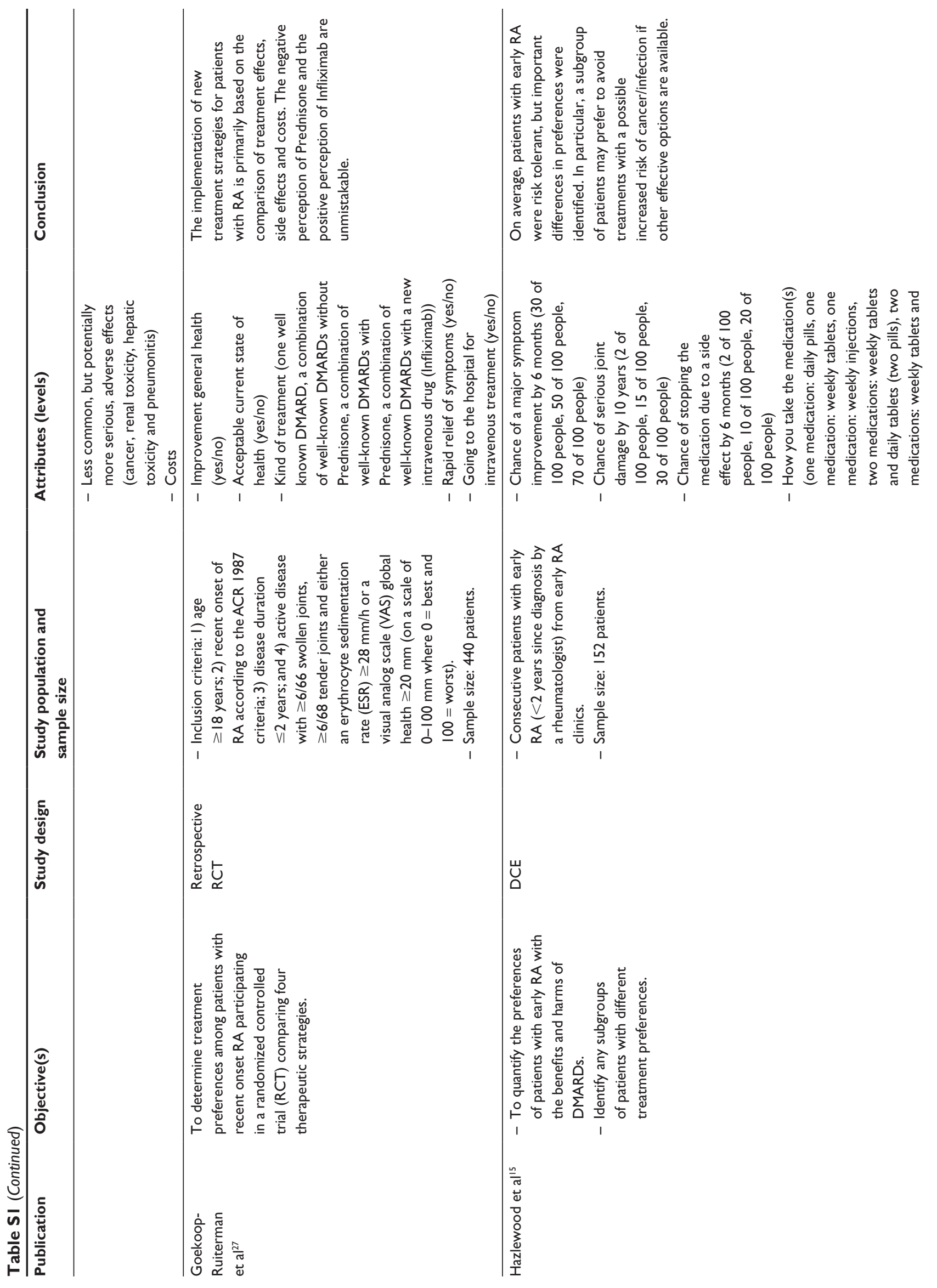




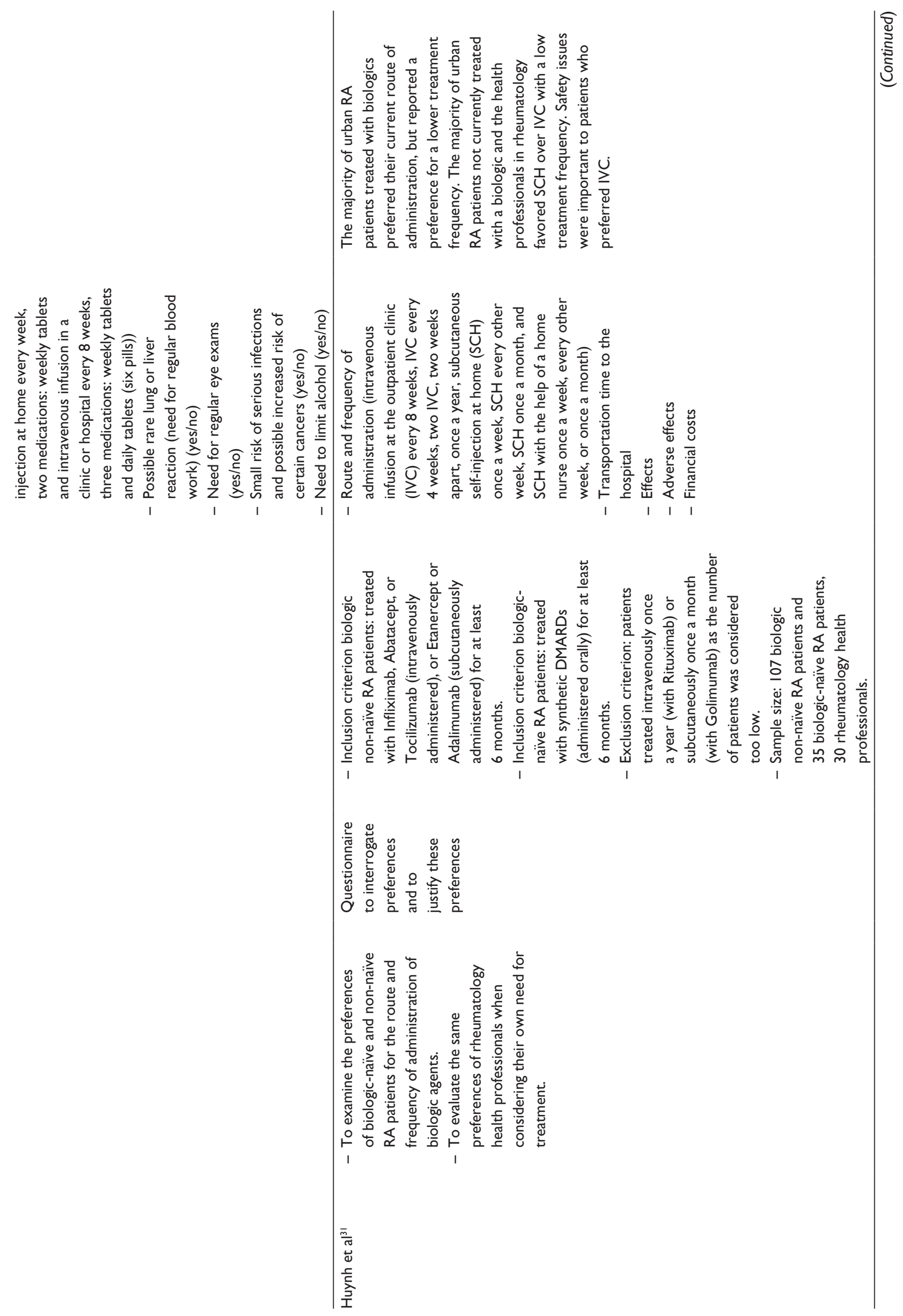




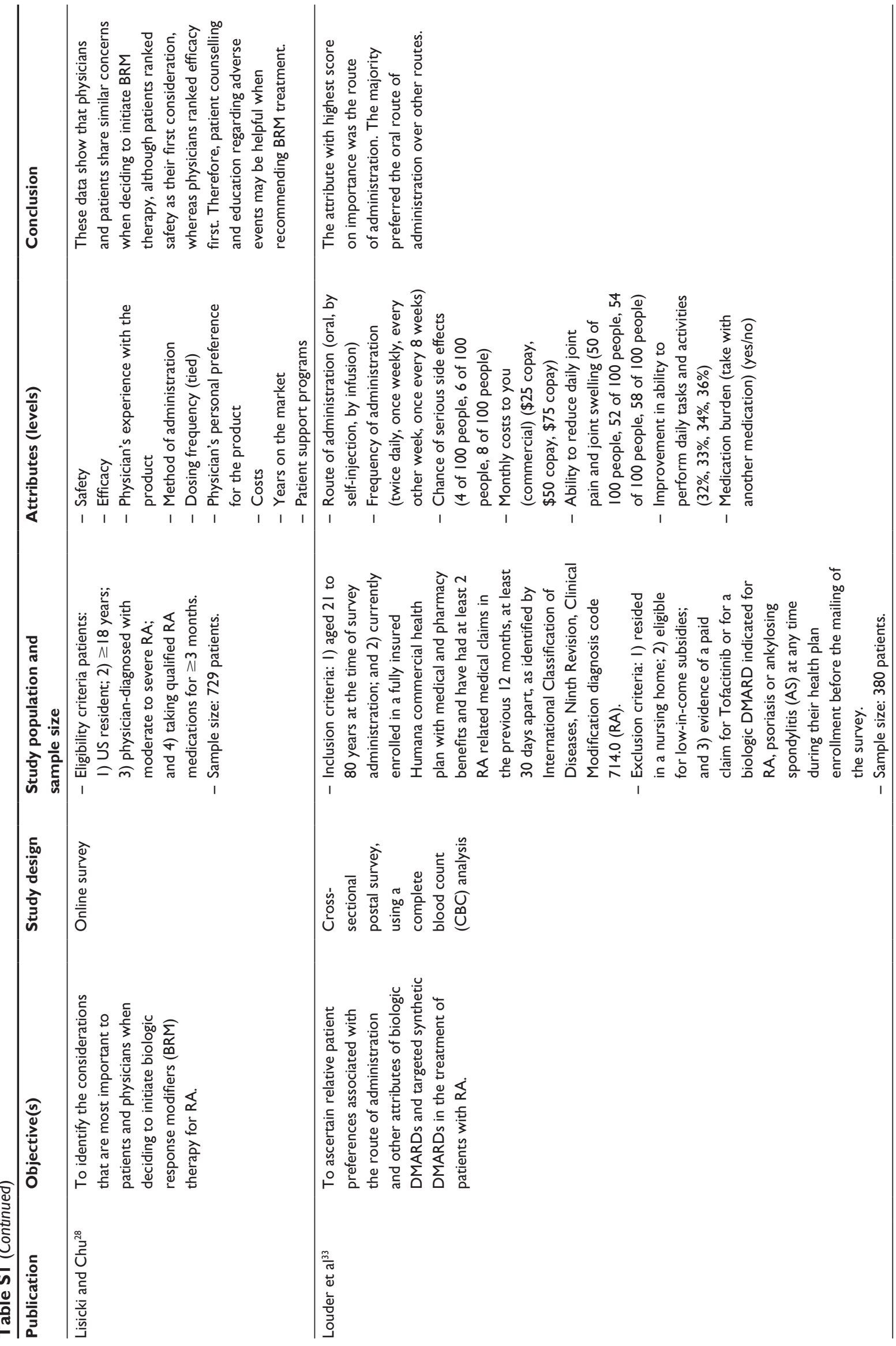



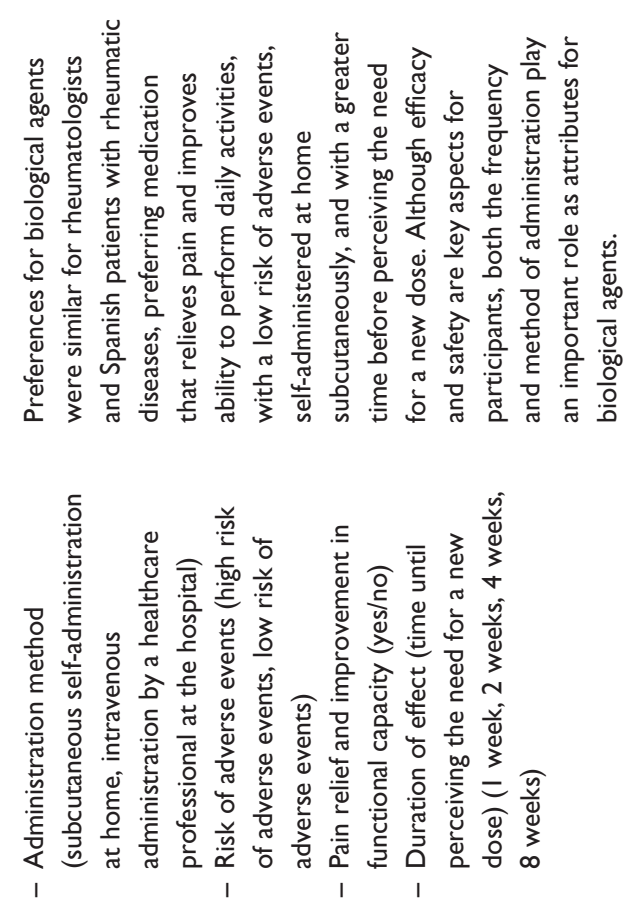
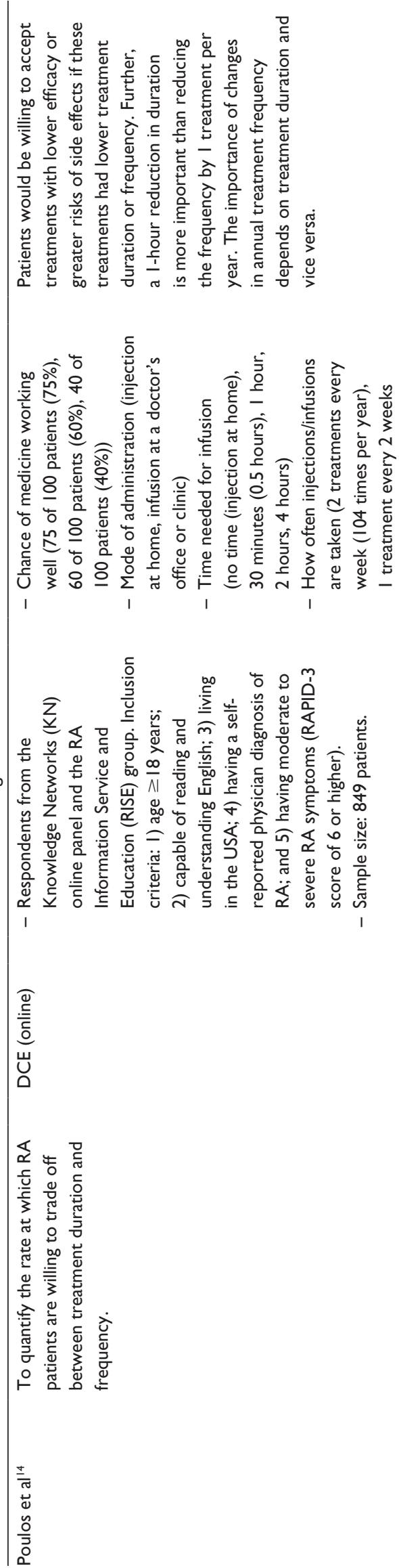

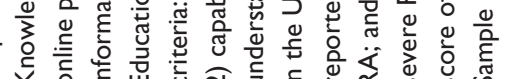

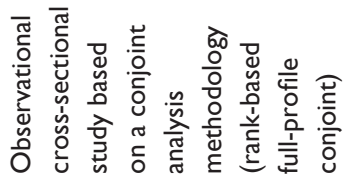

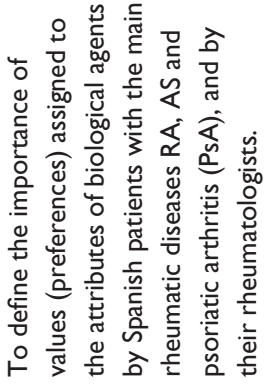

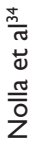

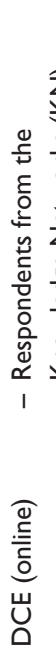

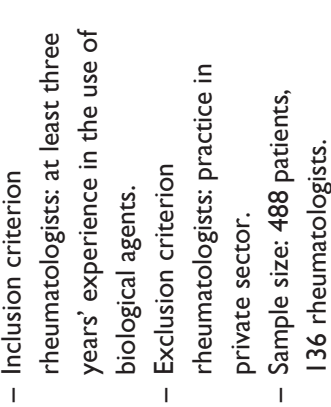

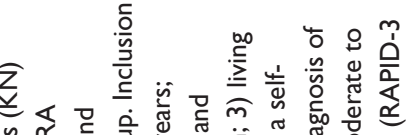

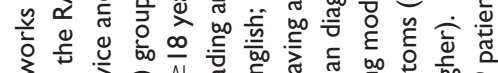

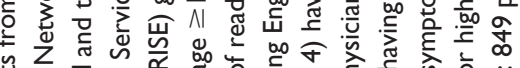

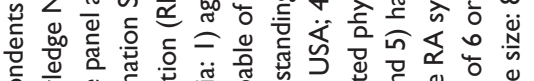

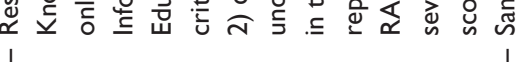




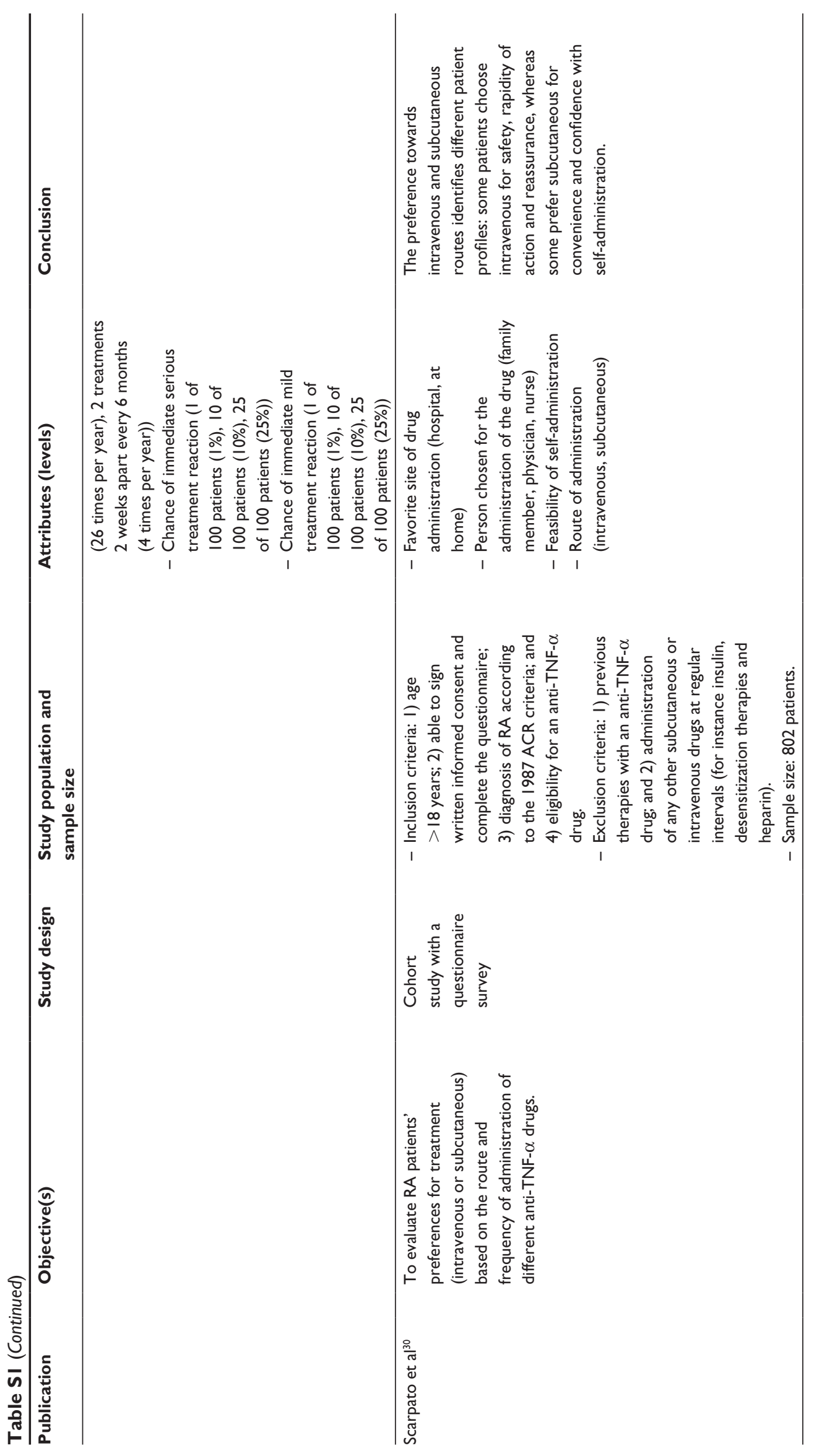


Table S2 Patients' rankings of attributes during the focus groups

\begin{tabular}{ll}
\hline Ranking & Attribute \\
\hline 1 & Risk of cancer $^{\mathrm{a}}$ \\
2 & Risk of liver injury $^{\mathrm{a}}$ \\
3 & Chance of efficacy $^{\mathrm{a}}$ \\
4 & Risk of joint damage $_{5}$ \\
6 & Onset of action $^{\mathrm{a}}$ \\
7 & Risk of serious infections \\
8 & Knowledge about long-term consequences of DMARD use \\
9 & Risk of gastrointestinal complications \\
10 & Route of administration \\
11 & Years of experience with DMARD to treat RA \\
12 & Risk of mouth ulcers \\
13 & Risk of headache or dizziness \\
14 & Location of administration \\
15 & Frequency of administration \\
16 & Combination therapy \\
17 & Risk of skin rash \\
18 & Time needed for infusion \\
19 & Risk of hair loss \\
20 & Chance of injection side reaction \\
21 & Required storage conditions \\
22 & Preparation of DMARD needed \\
\hline
\end{tabular}

Notes: Rank I means most relevant and rank 22 means least relevant. ${ }^{\mathrm{a} T h i s ~ a t t r i b u t e}$ was eventually included in the DCE.

Abbreviations: RA, rheumatoid arthritis; DCE, discrete choice experiment; DMARD, disease-modifying antirheumatic drug.

\section{Publish your work in this journal}

Patient Preference and Adherence is an international, peer-reviewed, open access journal that focuses on the growing importance of patient preference and adherence throughout the therapeutic continuum. Patient satisfaction, acceptability, quality of life, compliance, persistence and their role in developing new therapeutic modalities and compounds to optimize clinical outcomes for existing disease states are major areas of interest for the journal. This journal has been accepted for indexing on PubMed Central The manuscript management system is completely online and includes a very quick and fair peer-review system, which is all easy to use. Visit http://www. dovepress.com/testimonials.php to read real quotes from published authors.

\footnotetext{
Submit your manuscript here: http://www.dovepress.com/patient-preference-and-adherence-journal
} 